\title{
THE KLIPPEL-FEIL SYNDROME (Congenital webbed neck)
}

\author{
BY
}

\author{
H. S. MITCHELL, M.D., \\ Children's Memorial Hospital, Montreal, Canada.
}

Congenital anomalies of the vertebrae are not very uncommon, especially in the lumbar region. Those of the cervical region are much less frequently seen, especially of the type classified under the Klippel-Feil syndrome, or absence of the cervical spine. Although the deformity was probably recognized for many years before, it was not until Klippel and Feil in 1912, in the report of their case with the anatomical specimen, brought the condition into general observance that attention was more directly focussed upon it. Reports have been presented from many countries, chiefly from France. Within the last decade nine cases have occurred in the United States of America, but as far as can be learned none have been previously reported in Canada. Klippel and Feil described three outstanding features: shortening or absence of the nesk, low hair line, and limitation of the movements of the head and neck.

The condition is described as being always associated with diminution in number, and fusion, of the cervical vertebrae, and sometimes of the upper dorsal vertebrae. As there have been only about forty cases described altogether, and only two (as far as can be found) anatomical specimens, much of the information regarding the details of the deformity is based upon speculation and x-ray evidence.

Several theories are advanced regarding the etiology. The concensus of opinion is that the cause is a developmental aberration of unknown nature, affecting this group of vertebrae in early intra-uterine growth. Often there is associated fusion of the atlas to the occiput and in some cases there are nervous conditions (mirror movement and peripheral nerve lesions) although these are much less frequent than one would expect in such a pronounced deformity occurring about the upper cord.

There is commonly an appearance of spina bifida occulta, always at the upper extremity of the spine, triangular in shape with the base above, which does not seem to have given rise to any difficulty in itself.

Other congenital deformities may co-exist and are sometimes multiple. The head may be misshapen; there is usually more or less kyphosis; there may be slight scoliosis and, as in two of our cases, there may be visceral abnormalities also.

Diagnosis. - If the condition is seen in infancy, it may be treated at first as ordinary congenital torticollis of muscular origin, but without any benefit. 
Some patients are said to have undergone myotomy without the underlying cause being recognized. Later tuberculosis, syphilis and other infectious agents may be suspected. None of these conditions, or trauma, give rise to such a state present at and persisting from birth. If the features described by Klippel and Feil are borne in mind and a complete history taken, the diagnosis should present no great difficulty. X-ray examination is difficult on account of the conformation of the neck and its limitation of movement, but if skilfully made and interpreted, it should settle the diagnosis in most cases, as the findings are characteristic and unlike any other clinical condition.

Prognosis and treatment. - The deformity itself offers no impediment to a good expectation of life. The case of Klippel and Feil was a tailor of forty-eight. The condition is reported in a man of seventy. The mental

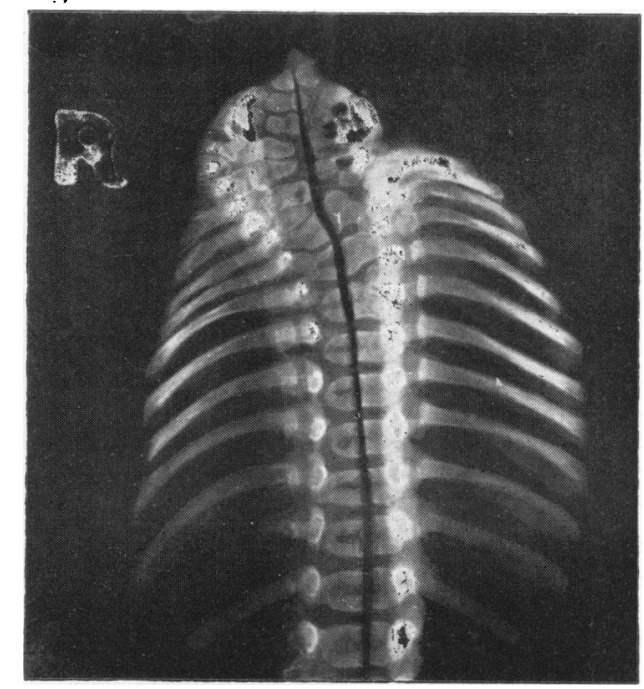

FIG. 1. Case 1.-Radiograph of vertebral column. The atlas is not included in the specimen. The superior fragment of cartilage is the odontoid process of the axis. The vertebral spines have been removed.

attitude is usually bright and not impaired. As to the treatment, the main points lie in the early recognition of the lesion and avoidance of misdirected therapy.

\section{Case reports.}

The following cases illustrate many of these points :-

Case 1. J. R., female, aged 5 weeks. Referred on account of deformity of the neck and head, malnutrition, cyanotic attacks and choking on feeding. The family history was negative. The mother fell downstairs at the fourth month of pregnancy : birth occurred at full term, a breech presentation with spontaneous delivery.

Physical examination: The child's head was turned to the right. There was partial paralysis of the right facial nerve and paralysis of both musculo-spiral nerves. The head was asymmetrical with the occiput flattened and the left side bulging in the parieto-occipital region. The neck was very short with the hair-line low behind. The trapezius on each side was taut, the margin projecting laterally, 
producing a webbed appearance. The head was flexed and the chin almost rested on the sternum. There was no motion of the head or neck in any direction except by motion of the whole trunk. On deep palpation in the upper cervical region a deficiency in the bones of the vertebrae could be felt. The heart was enlarged but no murmurs were audible. The child weighed four pounds at 5 weeks of age, was very emaciated and experienced considerable trouble in feeding, choking on nursing as if there was difficulty in swallowing; it became cyanosed when it cried. A series of respiratory infections developed from which the infant succumbed at the age of eleven weeks. X-ray examination of the cervical region disclosed gross deformities of the cervical and upper dorsal vertebrae which are described in the autopsy findings.

AUTOPSY FINDINGs. Apart from bilateral broncho-pneumonia, a supernumerary lobe of the right lung and a patent foramen ovale, the attention at autopsy was directed towards the vertebral column. There was moderate scoliosis with curvature

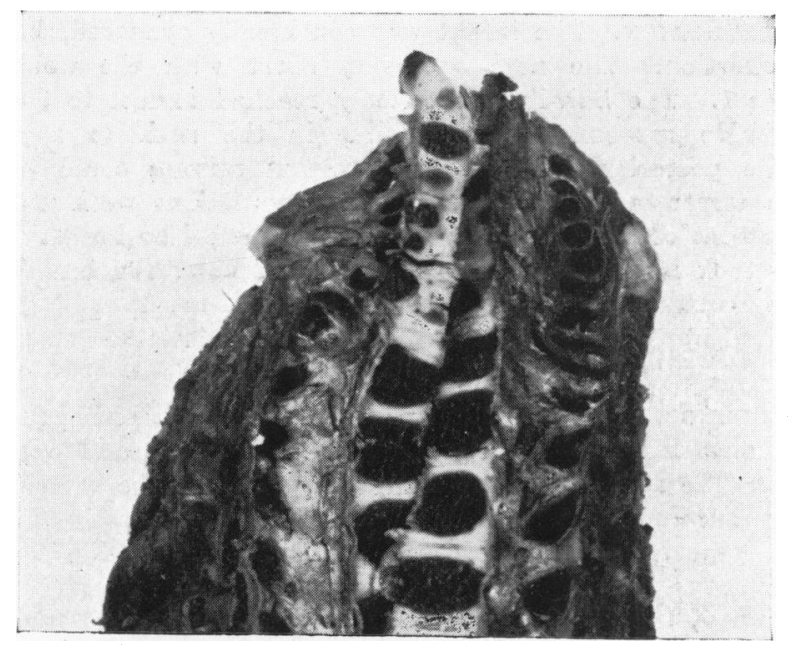

Fig. 2. Case 1.-The specimen as seen in Fig. 1 has been divided through the bodies of the vertebrae. Note the irregularity of the bodies and of the inter-vertebral foramina.

towards the right in the cervico-dorsal region. There were twelve ribs on the left side and eleven on, the right side with one rudimentary rib.

The occiput and atlas were fused. The intervertebral dises above the fourth dorsal were irregular or totally obliterated and one could not differentiate between one vertebra and another in this region. They were all fused together into one solid, bony, and cartilaginous mass.

The normal intervertebral foramina were all present on each side, that is, nineteen foramina on each side counting from the twelfth thoracic upwards. The first cervical nerve was not dissected out, but did not appear in its usual situation as the atlas and occiput were fused. It may have accompanied the second cervical nerve. In the cervical region the laminal arches instead of curving posteriorly and medially to enclose the vertebral canal, curved sharply downwards and medially, meeting their fellows of the opposite side in an irregularly fused mass at what would be about the normal level of the sixth and seventh cervical spines, thus creating a large open space triangular in shape, the base being towards the fused atlas and occiput. There was no meningocele. The anterior wall of the vertebral canal in this region was flattened out to four or five times its normal width, the greatest width being about the middle of the fused region, causing a distinctly oval shape. The intervertebral foramina appeared at the lateral extremity of the oval shaped 
area; each foramen was distinct, but in many cases only the very thinnest and most delicate bony and cartilaginous walls separated them.

X-RAy of anatomical Specimen: The dorsal vertebrae were normal up to the fourth dorsal, except that a hemi-vertebra above the fifth vertebra on the right side was seen. Above this the ossified centres were quite irregular, and as a vertebral body may come from one or two ossified centres, it was quite impossible to say how many whole bodies were involved in the fused portion. As the normal number of intervertebral foramina were present on each side, it seems justifiable to conclude that this fused region represents the number of segments corresponding to the normal number for the same area.

Case 2. D. C., female, aged 6 weeks. Referred on account of failure to gain weight, continual cyanosis and deformity of the neck. The family history was negative. Delivery was precipitate and occurred at full term. No history of antenatal injury was obtained.

Physical examination. The infant was continually cyanosed, but worse during crying or on exertion. The neck was very short with the webbed appearance described in case 1 . The hair-line posteriorly reached almost to the upper margin of the thorax. No movement was possible in the neck in any direction. A deficiency in the posterior part of the vertebral column could be felt on deep palpation in the upper cervical region. No nervous lesions were noted. There was no gross enlargement of the heart and no murmurs could be heard. The infant was very weak and took its feeds poorly. The general condition became progressively worse, death supervening at the age of $11 \frac{1}{2}$ weeks. X-ray showed gross deformities of the cervical and upper dorsal vertebrae. These are described in the post-mortem findings.

Autopsy findings. In addition to the spine described below, there were congenital anomalies in the heart-a patent foramen ovale and a patent interventricular septum. The atlas was fused with the occiput. The vertebral column was slightly scoliotic, curving towards the right in the upper dorsal and cervical region. The normal antero-posterior curvature of the spine in the cervical and dorsal region was not present, thus causing the upper part of the spine to be almost straight. The upper portion of the cervical column was slightly rotated horizontally, so that the head was held fixed at an angle of about 10 degrees to the main part of the column, and facing towards the right. There were twelve ribs on the right side, and eleven on the left with one rudimentary rib. The normal number of intervertebral foramina were present on each side, but the upper eight on each side were quite irregular in size and shape, being separated by thin, bony, and cartilaginous walls. There was no foramen for the first cervical nerve. The anterior wall of the vertebral canal was flattened out and broadened toward the occiput in a curved funnel-shaped fashion. The laminal arches instead of curving posteriorly, pointed downwards and posteriorly, each meeting its fellow of the opposite side and fusing with the lower one at about the junction of the dorsal and cervical region. This made a large uncovered space above, almost like an equilateral triangle with the base composed of united occiput and atlas. No true meningocele existed. The vertebral bodies were distinct up to the fourth dorsal; above that, the intervertebral dises became irregular with disappearance of the dises and irregularity in size and position of the bodies. Above the fourth dorsal there was present none of the normal flexibility of the vertebral column, the mass being more or less fused as one.

X-Ray OF THE anatomical SPEcimen: In the $x$-ray the irregularities of the cartilaginous dises were not apparent and the structure of the bodies appeared normal until the body of the second dorsal was reached; above this region the centres of ossification for the cervical group of vertebral bodies were very unusual. The dens had been incorporated into the body of the atlas and the upper two centres of ossification seen in the x-ray belonged to the body of the axis. The 
centres for the 3rd, 4th, 5th, 6th, and possibly the 7th cervical bodies were joined together and appeared to be ossifying in one irregular mass.

Case 3. C. O. Referred on account of deformity of the neck. The infant was a well-developed male weighing fifteen pounds at 6 months. The family history and ante-natal period were negative. The hair-line was low posteriorly, with lack of movement in any direction. The skull was asymmetrical and flattened on the right side. The right mastoid process was $2 \frac{1}{2}$ in. from the shoulder, the left being 5 in.; the face was rotated slightly to the left side. X-ray showed gross deformity of the superior vertebrae involving all the cervical and upper four or five dorsal vertebrae.

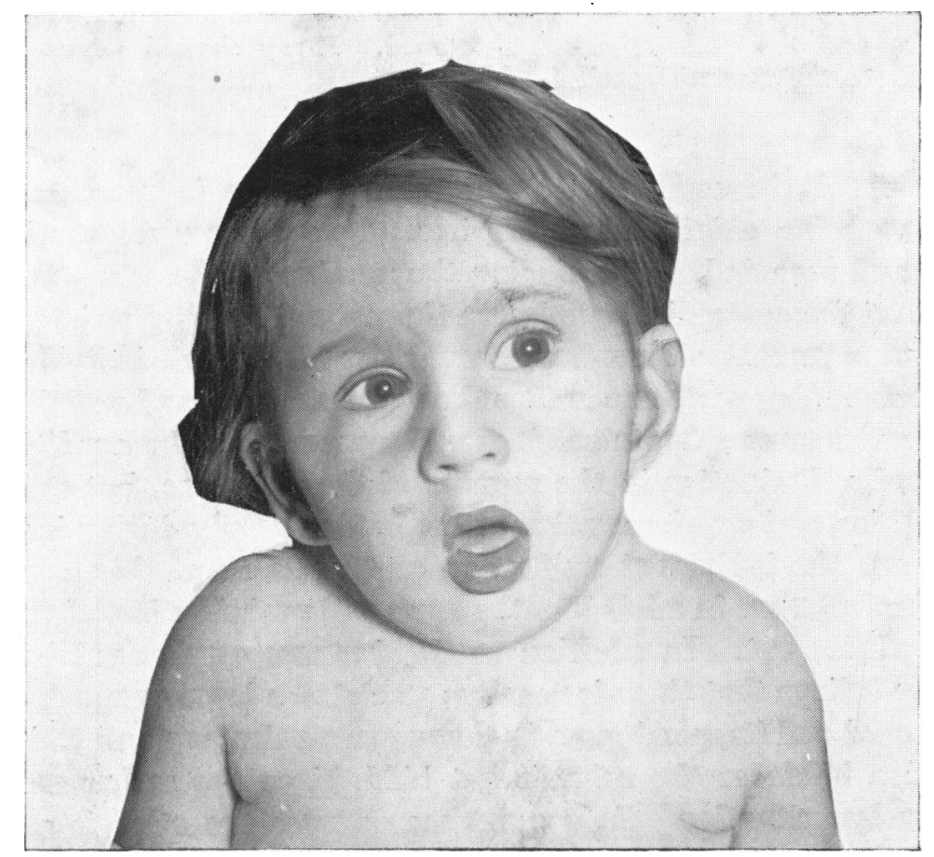

Fig. 3. Case 3.-Note that owing to the extreme shortness of the neck, the head appears to rest almost directly on the trunk. The position of the head is fixed as in the photograph.

This group appeared irregularly fused together with a broadened appearance near the occiput. The child has been under observation for about a year and is quite normal and active except as described.

Case 4. L. D. Referred on account of deformity of the neck. This was a well-developed male child of sixteen months weighing twenty-two pounds. The neck was short with marked limitation of movement in every direction. X-rays showed several anomalies of the cervical and upper dorsal vertebrae with irregular fusion and a narrow spina bifida in the upper cervical region. Otherwise the child was quite well, and developing normally.

Case 5. H. R. This was a female child of $9 \frac{1}{2}$ years, referred through the courtesy of Dr. Stocker, of Ormstown, Quebec. It was the result of the third pregnancy in a family of four, all of whom were instrumentally delivered. The mother fell about the middle of her pregnancy striking her abdomen a hard blow. H. R's. delivery was no more difficult than the others. There was no difficulty in feeding or nutrition during infancy. Development was normal; enuresis was present until $6 \frac{1}{2}$ years of age. Mirror movement was present in the upper extremities, but was becoming less noticeable. The mother stated that blows or other accidental injuries to the head were more painful than in the other children. "The mentality was quite good. 
Physical examination. Examination was entirely negative except with reference to the neck. The neck was very short, the hair-line at the back reaching almost to the shoulders, and the chin being very close to the sternum. There was no definite motion of the head or neck without the trunk. X-ray showed fusion of the upper five cervical vertebrae with loss of detail of the individual vertebrae. The 5th and 6th cervical vertebrae appeared normal.

Case 6. B. G., a female of 5 years, seen through the courtesy of Dr. W. G. Turner, of the Shriner's Hospital, Montreal. The child was a deaf mute with gross inco-ordinated movements of the hands and feet, resembling a torsion spasm. There was scoliosis towards the left, asymmetry of the skull, the head leaned toward the left shoulder and the neck appeared shortened. X-ray showed fusion of all the vertebrae above the seventh cervical.

\section{Discussion.}

A series of six cases of Klippel-Feil syndrome is presented with a description of the chief clinical features. Two anatomical specimens are described and recorded, thus bringing the number of these to at least four. As in each of the anatomical specimens the normal number of intervertebral foramina were present although one could not identify all individual bodies of the corresponding vertebrae and as the vertebral body and vertebral arches come from the same sclerotome, it would appear that the condition is the result not of a diminution in the number of the vertebrae, but rather of an irregular fusion and conglomeration of the bodies. Only during infancy and childhood can the individual ossification centres be seen. If the patient is seen for the first time in adult life, the mass will probably have been ossified into one whole part. In addition to the features emphasized by Klippel and Feil we believe that there is usually associated a large exposed portion of the spinal cord and its membranes in the upper cervical region. This is really a false spina bifida as the spine is not bifid, since the arches meet in an abnormally low situation. In a great many cases the atlas is assimilated into the occiput. It has been stated that there is a diminution in number of the cervical vertebrae, but it follows from what has been described above that is more correct to say that the diminution in number is apparent rather than real, and that the bodies and to a lesser extent the transverse processes, are irregularly associated with the incompletely segmented and rigid mass. It is therefore improper to speak of the condition as being due to an ' absence of the cervical spine' until more is learned of the etiology and organic nature of the condition. It is preferable to refer to it under the name of its original reviewers, or as ' congenital webbed neck.'

\section{REFERENCES.}

1. Klippel, M., \& Feil, A., Nouv. iconog. de la Salpêtrière, Paris, 1912, XXV, 223; Bull. et mém. Soc. Anat. de Paris, Paris, 1912, Sixth series, XIV, 185.

2. Bauman, G. I., J. Am. Med. Ass., Chicago, 1932, XCVIII, 129.

3. Smith G. E., Brit. Med. J., Lond., 1908, ii, 594.

4. Crouzon, O., \& Martin, R., Bull. et mém. Soc. méd. d. hôp. de Paris, Paris, 1923, XLVII, 1486.

5. Crouzon, O., \& Liege, R., Ibid., 1928, LII, 917.

6. Feil, A., J. de radiol. et d'électrol, Paris, 1923, VII, 125.

7. Noble, T. P., \& Frawley, J. M., Ann. Surg., Philad., 1925, LXXXII, 728, 